\title{
Aetiology of bilateral sensorineural hearing impairment in children: a 10 year study
}

\author{
V K Das
}

\begin{abstract}
The study was carried out on children born over a 10 year period from 1981 to 1990 in a defined area known as Greater Manchester and referred to the Centre for Audiology or the Manchester Royal Infirmary for specialist audiological assessment. The children were investigated for possible congenital or intrauterine infection. Perinatal assessment was carried out in conjunction with paediatricians for adverse aetiological factors. Full medical histories were obtained with detailed family history relevant to hearing impairment and any associated condition or syndrome. Parents and siblings were examined and hearing assessed. A total of 339 cases was studied. Children with positive family history of deafness in parents or siblings, or both, constituted $23.3 \%$ of the cases (genetic group). Other aetiological groups showed the following distribution: cause unknown $33.9 \%$; perinatal group $12 \cdot 8 \%$; congenital infections $8 \cdot 2 \%$; bacterial meningitis $6 \cdot 5 \%$; chromosomal anomalies $5 \cdot 3 \%$; syndromal group $5 \cdot 3 \%$; and miscellaneous group $4 \cdot 7 \%$. The high incidence of genetic causes indicates that steps should be taken to facilitate genetic counselling and conceivably to reduce the numbers affected.
\end{abstract}

(Arch Dis Child 1996; 74: 8-12)

Keywords: sensorineural deafness, genetic factors, aetiology.

Auditory deprivation causes serious impairment of the normal development of a child, especially in the field of normal communication and learning. If unrecognised or poorly managed it permanently affects development and emotional maturation, limits the acquisition of occupational and creative skills, and lowers the quality of life. Early diagnosis is essential to minimise or to prevent the disability. Aetiological diagnosis helps the clinicians involved to anticipate the prognosis and course of deafness. It is crucial for genetic counselling. The establishment of an aetiological diagnosis is essential in identifying and controlling the causative factors in the community; it may also help in regulating the preventive and management services to obtain cost-effective results. Regular surveillance is needed to show the outcome of preventive measures undertaken in the community, for example the vaccination programme against rubella, phototherapy for jaundice of prematurity, and so on. Comparing the data from various studies conducted in the same catchment area or region is the most effective way of assessing epidemiological changes with passing years. Previous reports ${ }^{1-4}$ from the Greater Manchester area have shown that there has been no significant change in overall prevalence of bilateral sensorineural hearing loss, but there has been a reduction in numbers of children with hearing impairment caused by preventable causes, for example congenital rubella infection. There is therefore a need to constantly update the epidemiological data as disease patterns and medical preventive and management practices change with time.

\section{Methods}

The present study was undertaken at the Centre for Audiology, Education of the Deaf and Speech Pathology, Manchester University, and the university department of otolaryngology and audiological medicine at Manchester Royal Infirmary, Manchester, during the period 1981 to 1994 on children born between 1981 and 1990 inclusive, from a defined area of Greater Manchester.

The full procedure of investigations as detailed in the protocol was carried out whenever the parents agreed at Royal Manchester Children's Hospital and Manchester Royal Eye Hospital (32\%); others were investigated by local paediatricians $(30 \%)$ or in the university department of otolaryngology and audiological medicine (38\%).

\section{AUDIOLOGICAL ASSESSMENT}

Children with a bilateral sensorineural hearing impairment averaging $30 \mathrm{dBHL}$ or over in the better ear within the frequency range of $250 \mathrm{~Hz}$ to $4 \mathrm{kHz}$ were included in the study. Audiological information from pure tone audiometry, speech tests, behavioural tests of hearing, ${ }^{5}$ visual reinforced audiometry, and brainstem evoked response tests were used to differentiate two hearing impaired groups, (1) $>30 \mathrm{dBHL}$ to $<80 \mathrm{dBHL}$, and $(2) \geqslant 80 \mathrm{dBHL}$. 
Table 1 (A) Distribution of children born 1981-1990 in various aetiological groups

\begin{tabular}{lcr}
\hline Aetiological group & No of children & \multicolumn{1}{c}{$\%$} \\
\hline Congenital rubella infection & 18 & $5 \cdot 3$ \\
Congenital CMV infection & 10 & $2 \cdot 9$ \\
Perinatal & 43 & $12 \cdot 8$ \\
Meningitis & 22 & $6 \cdot 5$ \\
Genetic & 79 & $23 \cdot 3$ \\
Chromosomal & 18 & $5 \cdot 3$ \\
Unknown & 115 & $33 \cdot 9$ \\
Syndromal & 18 & $5 \cdot 3$ \\
Miscellaneous & 16 & $4 \cdot 7$ \\
Total & 339 & 110 \\
\hline
\end{tabular}

(B) Distribution according to major aetiological groups *

\begin{tabular}{|c|c|c|c|c|}
\hline \multirow{2}{*}{$\begin{array}{l}\text { Aetiological } \\
\text { groups }\end{array}$} & \multicolumn{2}{|c|}{ Hearing impairment } & \multirow[b]{2}{*}{ Total } & \multirow[b]{2}{*}{$\%$} \\
\hline & $<80 \mathrm{dBHL}$ & $\geqslant 80 \mathrm{dBHL}$ & & \\
\hline $\begin{array}{l}\text { Prenatal } \\
\text { Perinatal } \\
\text { Postnatal } \\
\text { Unknown } \\
\text { Miscellaneous }\end{array}$ & $\begin{array}{r}65 \\
8 \\
5 \\
67 \\
7\end{array}$ & $\begin{array}{r}78 \\
35 \\
17 \\
48 \\
9\end{array}$ & $\begin{array}{r}143 \\
43 \\
22 \\
115 \\
16\end{array}$ & $\begin{array}{r}42 \cdot 2 \\
12 \cdot 7 \\
6 \cdot 5 \\
33 \cdot 9 \\
4 \cdot 7\end{array}$ \\
\hline Total & 152 & 187 & 339 & 100 \\
\hline
\end{tabular}

*Aetiological grouping as recommended by International

Association of Physicians in Audiology (IAPA), 1993.

Results in dBSPL and dBA were converted into equivalent $\mathrm{dBHL}$ values as described by Hine $^{6}$ using tables published by Nolan. ${ }^{7}$

PLAN OF INVESTIGATIONS

The investigation protocol is given in the appendix. Comments from paediatricians, neurologist, radiologist, pathologist, endocrinologist, and psychologist were obtained so as to provide the most probable aetiological diagnosis and a full description of associated disabilities.

\section{Results}

A total of 339 cases satisfied the audiological diagnostic criteria during the study period. The average number of children born in the county was over 30000 per year during the period of the study, which gave a prevalence rate of hearing impairment of $1 \cdot 13 / 1000$ births.

The distribution of children in the various aetiological groups is shown in table 1 .

\section{DEGREE OF HEARING LOSS}

The prevalence of the $\geqslant 80 \mathrm{dBHL}$ group was greater than the $<80 \mathrm{dBHL}$ group, at $55 \% v$ $45 \%$. The distribution of children according to the degree of hearing loss and the audiological tests employed is shown in table 2 . Tables 3 and 4 show the distribution of children according to the degree of hearing loss in the various aetiological groups.

\section{FAILURE OF SCREENING TESTS AND AGE AT DIAGNOSIS}

In Greater Manchester the screening for hearing impairment is conducted by health visitors using modified free field distraction testing ${ }^{5}$ at approximately 9 months of age. False negative results were noted in $32 \%$ of all children identified, with a range of $9 \%$ to $39 \%$ in various districts, possibly reflecting the efficiency of the testers. Detection rates were better in the second half of the study period by approximately $12 \%$. The mean age of diagnosis was found to be just over 21 months in the children born in the first five years of the study. The mean age of diagnosis fell to 19 months in the second half of the 10 year period. Thus there was evidence of slight improvement in early identification of hearing impaired children born in the later years.

\section{SEX RATIO}

A male preponderance was found in most groups, particularly the meningitis and perinatal groups. A female prepondence was found in the chromosomal group. The details of the sex ratio are shown in table 3.

\section{ASSOCIATED CONDUCTIVE HEARING LOSS}

Associated conductive hearing loss can add up to $40 \mathrm{dBHL}$ loss to the underlying sensorineural deafness and may therefore impose a significant problem in assessing the extent of any sensorineural loss. A total of 73 cases $(22 \%)$ was diagnosed as having a persistent conductive overlay secondary to secretory otitis media or otitis media with effusion requiring surgical treatment at least on one occasion. A large

Table 2 Distribution of children according to the degree of hearing loss and the audiological tests employed

\begin{tabular}{lllll}
\hline $\begin{array}{l}\text { Degree of } \\
\text { hearing loss }\end{array}$ & $\begin{array}{l}\text { Total } \\
\text { No (\%) }\end{array}$ & PTA & $\begin{array}{l}\text { Behavioural } \\
\text { tests }\end{array}$ & BSER \\
\hline$<80$ dBHL & $152(45)$ & 133 & 27 & 15 \\
$\geqslant 80$ dBHL & $187(55)$ & 146 & 39 & 23 \\
Total & 339 & 279 & 66 & 38
\end{tabular}

$\mathrm{BSER}=$ brain stem evoked response test.

Table 3 Sex distribution in different aetiological groups

\begin{tabular}{lrrrl}
\hline Aetiological group & Male & Female & Total & $\begin{array}{l}\text { Male } \\
\text { female ratio }\end{array}$ \\
\hline Congenital rubella infection & 10 & 8 & 18 & $1 \cdot 25$ \\
Congenital CMV infection & 5 & 5 & 10 & $1 \cdot 00$ \\
Perinatal & 28 & 15 & 43 & $1 \cdot 86$ \\
Meningitis & 16 & 6 & 22 & $2 \cdot 66$ \\
Genetic & 49 & 30 & 79 & $1 \cdot 63$ \\
Chromosomal & 8 & 10 & 16 & $0 \cdot 80$ \\
Unknown & 63 & 52 & 115 & $1 \cdot 21$ \\
Syndromal & 11 & 7 & 18 & $1 \cdot 57$ \\
Miscellaneous & 8 & 8 & 16 & $1 \cdot 00$ \\
Total & 198 & 141 & 339 & $1 \cdot 40$ \\
& & & &
\end{tabular}

Table 4 Distribution of degree of hearing loss in various aetiological groups; values are number (\%)*

\begin{tabular}{lrr}
\hline & \multicolumn{2}{c}{ Degree of hearing loss } \\
\cline { 2 - 3 } & $\begin{array}{c}<80 \mathrm{dBHL} \\
(n=152)\end{array}$ & $\begin{array}{c}\geqslant 80 \mathrm{dBHL} \\
(n=187)\end{array}$ \\
Group & $3(20)$ & $15(80)$ \\
Congenital rubella infection $(\mathrm{n}=18)$ & $3(30)$ & $7(70)$ \\
Congenital CMV infection $(\mathrm{n}=10)$ & $8(19)$ & $35(81)$ \\
Perinatal $(\mathrm{n}=43)$ & $5(23)$ & $17(77)$ \\
Meningitis $(\mathrm{n}=22)$ & $43(54)$ & $36(46)$ \\
Genetic $(\mathrm{n}=79)$ & $6(33)$ & $12(67)$ \\
Chromosomal $(\mathrm{n}=18)$ & $67(58)$ & $48(42)$ \\
Unknown $(\mathrm{n}=115)$ & $10(56)$ & $8(44)$ \\
Syndromal $(\mathrm{n}=18)$ & $7(44)$ & $9(56)$ \\
Miscellaneous $(\mathrm{n}=16)$ & $152(45)$ & $187(55)$ \\
Total &
\end{tabular}

^Percentages rounded off. 
Table 5 Children with additional disability in various aetiological groups

\begin{tabular}{lccc}
\hline & & \multicolumn{2}{c}{$\begin{array}{l}\text { Children with } \\
\text { additional disability }\end{array}$} \\
\cline { 2 - 4 } Aetiological groups & Total & No & $\%^{\star}$ \\
\hline Congenital rubella infection & 18 & 8 & 44 \\
Congenital CMV infection & 10 & 8 & 80 \\
Perinatal & 43 & 26 & 60 \\
Meningitis & 22 & 7 & 32 \\
Genetic & 79 & 8 & 10 \\
Chromosomal & 18 & 18 & 100 \\
Unknown & 115 & 11 & 10 \\
Syndromal & 18 & 5 & 28 \\
Miscellaneous & 16 & 15 & 94 \\
& & &
\end{tabular}

$\star$ Percentages rounded off.

number was found to have a mild degree of otitis media for a total period of three months or more but did not require surgical treatment. The aetiological groups with congenital infections, perinatal damage, or chromosomal anomalies had increased instances of conductive problems as compared to genetic and unknown groups. Details of some of these findings have been reported in another paper. ${ }^{8}$

\section{ADDITIONAL DISABILITIES}

A significant number of children showed evidence of additional disabilities, as shown in table 5. The commonest additional disability was developmental delay, followed by visual impairment.

Various aetiological groups are compared in table 6 . The individual groups were as follows.

\section{Congenital rubella syndrome}

All cases diagnosed satisfied the diagnostic criteria as published by Cradock-Watson et al. ${ }^{9}$ Approximately half the cases showed clinical evidence of congenital infection, with hepatosplenomegaly and skin lesions at the time of birth. Over $60 \%$ of cases had multisystem disease. Four cases showed evidence of progressive deterioration in hearing levels (mean deterioration of over $20 \mathrm{dBHL}$ in the frequency range of $250 \mathrm{~Hz}$ to $4 \mathrm{kHz}$ ).

\section{Congenital cytomegalovirus infection}

There were 10 cases where intrauterine cytomegalovirus (CMV) infection was confirmed by demonstration of specific IgM antibodies in the first two weeks of life. In six cases CMV was cultured repeatedly from urine and in three instances from the throat swab. In five

Table 6 Comparison with previous studies from Greater Manchester in children with a hearing loss $\geqslant 80 \mathrm{dBHL}$; values are number (\%)*

\begin{tabular}{lccc}
\hline & $\begin{array}{c}\text { Taylor } \\
(1980)\end{array}$ & $\begin{array}{l}\text { Newton } \\
(1985)\end{array}$ & $\begin{array}{c}\text { Present } \\
\text { study }\end{array}$ \\
\hline Congenital rubella infection & $19(30)$ & $7(12)$ & $15(8)$ \\
Congenital CMV infection & $7(11)$ & $2(3)$ & $7(4)$ \\
Perinatal & $12(19)$ & $8(13)$ & $35(19)$ \\
Meningitis & $4(7)$ & $4(7)$ & $17(9)$ \\
Genetic, chromosomal, and syndromal & $0(0)$ & $15(25)$ & $56(30)$ \\
Unknown & $19(30)$ & $24(40)$ & $48(25)$ \\
Others & $2(3)$ & $0(0)$ & $9(5)$ \\
Total & $63(110)$ & $60(100)$ & $187(100)$ \\
\hline
\end{tabular}

${ }^{\star}$ Percentages rounded off. children there was evidence of progressive deterioration of hearing levels.

\section{Perinatal group}

Forty three cases classified under this group were divided into two subgroups, (1) preterm and (2) term and post-term. Children in the preterm group suffered from one or more of the following conditions: birth asphyxia, respiratory distress syndrome, apnoea, assisted respiration, intraventricular haemorrhage, infections, or hyperbilirubinaemia needing phototherapy and exchange transfusion. Preterm children formed significantly the largest subgroup. Term and post-term children suffered from severe birth asphyxia and infections.

\section{Meningitis}

Twenty two cases suffered bilateral sensorineural hearing impairment as a complication of bacterial meningitis. There was a delay of over eight months between the episode of meningitis and the time of diagnosis and amplification in the first half of the period (1981-1985). The delay was reduced to five months for children born in the second half (1986-1990).

\section{Genetic group}

Seventy nine children with a positive family history confirmed by examination and testing were identified under this group. There were no known dysmorphic features, or clinical or biochemical abnormalities. In over two thirds of children the mode of transmission was considered to be mendelian autosomal recessive. Children from ethnic minorities were overrepresented in this aetiological group. Information related to possible aetiological factors in the ethnic minority groups, consanguinity, and other cultural factors has not been considered here.

\section{Chromosomal abnormalities}

Eighteen children were diagnosed as having chromosomal anomalies. The largest group $(n=6)$ had defects of chromosome 21. Other children were found to have anomalies of chromosomes 18, 17, 13, 12, 10, and X.

\section{Unknown group}

The largest group of all consisted of 115 children. In these children there was no known history of sensorineural deafness, no dysmorphic feature associated with known syndromes associated with deafness, and no known infective or biochemical cause could be established. Children were moved to the genetic group following the birth of another sibling with sensorineural loss, where no other acquired cause could be established.

\section{Syndromal and miscellaneous groups}

A total of 18 cases was found to be suffering from the following syndromes: Waardenburg, 
Table 7 Distribution of hearing loss under hereditary, acquired, and unknown groups from various reports

\begin{tabular}{|c|c|c|c|c|c|c|c|c|}
\hline \multirow[b]{2}{*}{ Author } & \multirow{2}{*}{$\begin{array}{l}\text { No } \\
\text { studied }\end{array}$} & \multirow{2}{*}{$\begin{array}{l}\text { Fence level of } \\
\text { hearing loss }\end{array}$} & \multicolumn{2}{|c|}{ Hereditary } & \multicolumn{2}{|c|}{ Acquired } & \multicolumn{2}{|c|}{ Unknown } \\
\hline & & & No & $\%$ & No & $\%$ & No & $\%$ \\
\hline $\begin{array}{l}\text { Fraser } 1964 \\
\text { Ruben } 1971 \\
\text { Taylor } 1975 \\
\text { Kankkunem } 1982 \\
\text { Parving } 1984 \\
\text { Newton } 1985 \\
\text { Present study }\end{array}$ & $\begin{array}{r}2355 \\
348 \\
86 \\
176 \\
117 \\
111 \\
339\end{array}$ & $\begin{array}{l}\text { Hearing impaired, deaf } \\
>30 \mathrm{dBHL} \\
\text { Hearing impaired, deaf } \\
>25 \mathrm{dBHL} \\
>35 \mathrm{dBHL} \\
>25 \mathrm{dBHL} \\
>30 \mathrm{dBHL}\end{array}$ & $\begin{array}{r}756 \\
74 \\
21 \\
99 \\
56 \\
33 \\
115\end{array}$ & $\begin{array}{l}32 \\
21 \\
24 \\
55 \\
48 \\
30 \\
34\end{array}$ & $\begin{array}{r}753 \\
136 \\
41 \\
51 \\
49 \\
35 \\
93\end{array}$ & $\begin{array}{l}32 \\
39 \\
48 \\
29 \\
42 \\
32 \\
27\end{array}$ & $\begin{array}{r}846 \\
138 \\
24 \\
29 \\
12 \\
43 \\
131\end{array}$ & $\begin{array}{l}36 \\
40 \\
28 \\
25 \\
11 \\
39 \\
39\end{array}$ \\
\hline
\end{tabular}

Hurler, Hunter, Marshall Stickler, Klippel Feil, occulocutaneous-albinism, and branchio-otorenal.

Sixteen children, mostly with multiple congenital anomalies, especially those affecting nervous system with associated sensorineural hearing impairment, could not be classified and were placed under a miscellaneous group.

\section{Discussion}

The prevalence of hearing impairment as reported by various investigators $\left({ }^{10-13}\right.$, and Parving A, personal communication) is compared in table 7 but true comparison is not possible owing to differences in criteria or fence level used, except for the study reported by Kankkumen in $1982 .{ }^{12}$ The present study is compared with two previous studies ${ }^{2}$ from Manchester which each consisted of 4-year cohorts. The prevalence rate for sensorineural loss in the better ear of $80 \mathrm{dBHL}$ or above was found to be slightly higher, at 0.55 per 1000 births, in the present study but the difference was not statistically significant. I believe the prevalence rate in the previous Manchester studies was an underestimate by at least $10-20 \%$, as no provision was made for families who moved out of the area and information could not be completed for a number of cases.

Although there was a slight difference in the criteria or threshold level for hearing impairment used in this study (for example, Taylor and Newton used average losses of $25 \mathrm{dBHL}$ as the cut off point in their studies, while in the present study the fence level or cut off point was fixed at $>30 \mathrm{dBHL}$ ), the differences in distribution found in some groups, such as congenital rubella infection, are unlikely to be significantly affected by these criteria. The findings in the more severely deaf group ( $>80 \mathrm{dBHL}$ ) are more comparable as similar criteria were used for previous reports and the present study (table 7 ).

The screening test carried out by the health visitors using the modified free field distraction test ${ }^{5}$ was followed in most of the districts and it was disappointing to note that over $32 \%$ of children were wrongly 'passed', that is, there was a false negative result. There was evidence of improvement in the detection rate between the first and the second half of the study period.

A male prepondance in the sex ratio was found for the meningitis and perinatal groups. Fisch $^{14}$ and Fraser ${ }^{10}$ have reported a higher proportion of males among children with hearing loss considered to be caused by hyperbilirubinaemia or respiratory problems.

The number of congenital rubella cases continues to decrease. The expected increase in numbers of cases of CMV infection was not seen, but this could be a result of the strict diagnostic criteria followed in the present study. Peckham et $a l^{15}$ and Best $^{16}$ have reported a higher prevalence of congenital CMV infection causing hearing loss, but have highlighted the difficulty of confirming the diagnosis of congenital infection.

The numbers of children in the perinatal group appear to have grown; this could reflect reduced mortality in preterm babies looked after in specialised neonatal units. Information from the present study and an earlier report ${ }^{4}$ will help audiologists to develop guidelines for targeting screening programmes. Results from the present study involving the children born in 1981-1985 in Greater Manchester showed that the majority of those with hearing impairment belonged to the preterm subgroup. ${ }^{17}$ Further work has shown that high frequency hearing thresholds are vulnerable to adverse perinatal factors, for example preterm delivery and low birthweight, hypoxia, respiratory distress syndrome, and apnoea; losses of very high frequencies have been shown to occur in such cases. ${ }^{18}$

The genetic group was the second largest, with $23.3 \%$ of all affected children. Meningitis continues to be a significant group (6.5\% of all children affected) and remains the most common cause of acquired sensorineural hearing loss in children. An improvement was noticed in the time taken in diagnosis of postmeningitis cases and hearing aid fitting in the second half of the 10 year period of the study. This may be a reflection of better awareness of the complication of deafness following meningitis. Children who were originally placed in other aetiological groups, for example the 'unknown' group, were transferred to the genetic group following the birth of a sibling with sensorineural hearing loss when investigations showed no other acquired cause.

The unknown aetiology group continues to be the largest group, with $33.9 \%$ of all cases. Segregation ratios calculated by Taylor, $^{1}$ Newton, ${ }^{3}$ and Das $^{4}$ have shown that the majority of children in the unknown group, in which environmental and acquired causes have been excluded, probably acquire their deafness by autosomal recessive inheritance. Fraser ${ }^{10}$ has also concluded in his extensive study that autosomal recessive genes are responsible for a majority of the cases of unknown aetiology. This information has been useful for genetic counselling for the families.

CONCLUSIONS AND RECOMMENDATIONS The present study shows the changing pattern 
of the epidemiology of sensorineural hearing impairment in young children. The prevalence rates obtained in this 10 -year cohort study provide reliable data for use in service planning. The study highlights the poor results of the present screening arrangements for hearing impaired children. Early identification of deafness in children at risk, that is, with congenital or acquired infections, various adverse perinatal factors, craniofacial abnormalities, or a positive family history, should be achieved by screening all children admitted to neonatal special care or intensive care units. The study clearly shows, however, that focusing only on the 'at risk' group will lead to less than half the affected children being identified; therefore cost-effective methods for universal screening are needed. Otoacoustic emission screening may be a possible answer.

This study has shown that public health measures have been effective in reducing the prevalence of congenital rubella as a cause of hearing impairment. Although there was slight improvement in the early identification of hearing impairment, as shown by lowering of the age of diagnosis towards the later half of the study period, it still falls short of the standards advocated by the National Deaf Childrens Society. ${ }^{19}$ Difficulties encountered with the diagnosis of congenital CMV infection were highlighted. Paediatricians need to be more aware of the condition so that the diagnosis of congenital infection is suspected and confirmed early in the neonatal period.

A smaller group of children who may have deafness of late onset or suffer from progressive hearing loss needs identification. Better awareness on behalf of parents and teachers, and regular school screening, will help in early diagnosis. Follow up of children after meningitis needs further improvement. Clinicians, parents, and teachers need to be more aware of deafness as a complication of meningitis, and management should help to provide adquate follow up arrangements, including hearing tests.

The adverse perinatal group which formed a significant proportion of deaf children needs further study to help target screening programmes. Segregation ratios as published previously from Manchester ${ }^{134}$ have helped in genetic counselling of families with siblings placed under the 'unknown' group. Genetic causes are now a majority and further improvement in this field will facilitate genetic counselling and possible reduction in the numbers.

I thank Professor J Bamford, Dr D Price, Dr V Newton, Mrs E McSporran, Mrs V Rowson, Miss J Clancy, and other staff members, various hospital and community doctors for their assistance, and Emeritus Professor I G Taylor for guidance and encouragement for the study.

\section{Appendix}

Investigation protocol

HISTORY

- Developmental history

- Obstetric and neonatal history

- Past and family history

EXAMINATION

- General and systemic examination - any dysmorphic features and pigmentary abnormality

- Developmental assessment

- Eye examination including fundoscopy

\section{INVESTIGATIONS}

- Thyroid function tests

- Serology for congenital infection: rubella, cytomegalovirus, herpes simplex, toxoplasmosis, syphilis if indicated

- Renal function tests: test for proteinuria; microscopic examination; CMV urine culture

- Electrocardiography

- Radiology

1 Taylor IG. The pattern of sensorineural hearing loss in babies and young children. In: Proceedings of the Scientific Meeting of the British Association of Audiological Physicians Meeting of the British Association of Audiological Physicians
and Community Paediatric Group, 1981. Manchester: Department of Audiology, Education of the Deaf and Department of Audiology, Education of

2 Taylor IG, Hine WD, Brasier VJ, Chiveralls K, Morris T. A study of the causes of hearing loss in a population of deaf children with special reference to genetic factors. $\mathcal{F}$ Laryngol Otol 1975; 89: 899-914.

3 Newton VE. Aetiology of bilateral sensorineural hearing loss in young children. $\mathscr{f}$ Laryngol Otol 1985; suppl 10

4 Das VK. Aetiology of bilateral sensorineural deafness in children. $f$ Laryngol Otol 1988; 102: 975-80.

5 Ewing IR, Ewing AWG. Ascertainment of deafness in infancy and early childhood. F Laryngol Otol 1944; 59: 309-15.

6 Hine WD. How deaf are deaf children? Br 7 Audiol 1973; 7: 41-4.

7 Nolan $M$. Guidance on interpretation of information from a sound level meter. $\mathcal{f} \mathrm{Br}$ Assoc Teachers Deaf 1978; 2: sound leve

8 Das VK. Prevalence of otitis media with effusion in children with bilateral sensorineural hearing loss. Arch Dis Child 1990; 65: 757-9.

9 Cradock-Watson JE, Bourne MS, Vandervedal ME. IgG IgA and IgM responses in acute rubella determined by the immunofluorescent techniques. F Hyg 1972; 70: 473-6.

10 Fraser GR. In: The causes of profound deafness in childhood. Baltimore: Johns Hopkins University Press, 1976.

11 Ruben RJ, Rozycki D. Clinical aspects of genetic deafness. Ann Otol Rhinol Laryngol 1971; 80: 255-63.

12 Kankkumen A. Preschool children with impaired hearing in Goteborg 1964-1980. Acta Otolaryngol 1982; suppl 1: 391.

13 Parving A. Aetiological diagnosis in hearing-impaired children - clinical value and application of a modern examination ren-clinical value and application of a modern examination

programme. Int $\mathcal{f}$ Pediatr Otorhinolaryngol 1984; 7: 29-38.
14 Fisch L. Sex-ratio and congenital deafness. In: Stephens SDG, ed. Disorders of auditory function II. London: SDG, ed. Disorders of

15 Peckham CS, Stark O, Dudgeon JA, Martin JAM, Hawkins Geckham CS, Stark O, Dudgeon JA, Martin JAM, Hawkins neural hearing loss. Arch Dis Child 1987; 62: 1233

16 Best JM. Congenital cytomegalovirus infection. BMF 1987; 294: 1140 .

17 Das VK. Adverse perinatal factors in causation of sensorineural hearing impairment in young children, Int $\mathcal{f}$ Pediatr Otorhinolaryngol 1991; 21: 121-5.

18 Razi MS, Das VK. Effects of adverse perinatal events on hearing. Int $\mathcal{F}$ Pediatr Otorhinolaryngol 1994; 30: 29-40.

19 Quality Standards in Paediatric Audiology. London: The National Deaf Children's Society, 1994. 